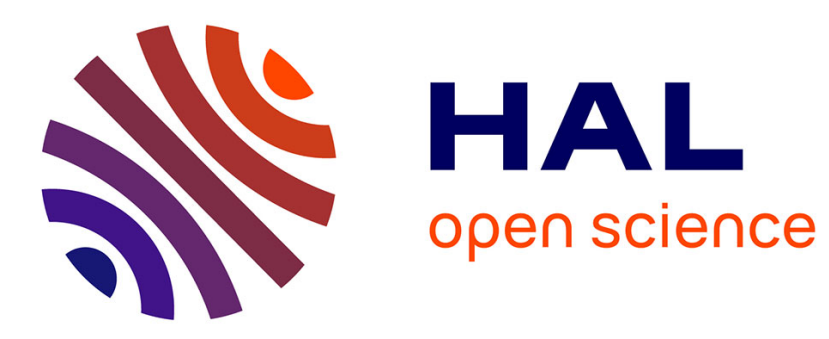

\title{
Scanning Tunneling Microscopy of the Na/Ge(111)3x1
}

D. Jeon, T. Hashizume, T. Sakurai

\section{- To cite this version:}

D. Jeon, T. Hashizume, T. Sakurai. Scanning Tunneling Microscopy of the Na/Ge(111)3x1. Journal de Physique IV Proceedings, 1996, 06 (C5), pp.C5-189-C5-194. 10.1051/jp4:1996531 . jpa-00254410

\section{HAL Id: jpa-00254410 https://hal.science/jpa-00254410}

Submitted on 1 Jan 1996

HAL is a multi-disciplinary open access archive for the deposit and dissemination of scientific research documents, whether they are published or not. The documents may come from teaching and research institutions in France or abroad, or from public or private research centers.
L'archive ouverte pluridisciplinaire HAL, est destinée au dépôt et à la diffusion de documents scientifiques de niveau recherche, publiés ou non, émanant des établissements d'enseignement et de recherche français ou étrangers, des laboratoires publics ou privés. 
JOURNAL DE PHYSIQUE IV

Colloque C5, supplément au Journal de Physique III, Volume 6, septembre 1996

\title{
Scanning Tunneling Microscopy of the $\mathrm{Na} / \mathrm{Ge}(111) 3 \times 1$
}

\author{
D. Jeon, T. Hashizume* and T. Sakurai** \\ Department of Physics, Myong Ji University, Yongin, Kyunggi-Do, Seoul 449-728, Korea \\ * Advanced Research Laboratory, Hitachi Ltd., Hatoyama, Saitama 350-03, Japan \\ ** Institute for Materials Research, Tohoku University, Sendai 980, Japan
}

\begin{abstract}
The structure of the Na/Ge(111) surface has been studied using scanning tunneling microscopy. Na atoms adsorbed preferentially on the domain boundaries and defect sites. At the increased coverage, Na atoms did not form an ordered structure. When the Na-adsorbed surface was annealed, the surface reconstructed to the 3x1 structure. The atomic arrangement of the $3 \times 1$ surface was similar to that of the $\mathrm{Na} / \mathrm{Si}(111) 3 \times 1$ surface.
\end{abstract}

\section{INTRODUCTION}

Alkali metal-adsorbed surfaces have been considered as a model system in surface science. This is due to the simple electronic configuration and low electronegativity of the alkali metals, and rich surface reconstruction and enhanced surface reactivity induced by alkali metals. One of the recent examples which has attracted an attention is the Na-induced $3 \times 1$ structure on the Si(111) surface [1-5]. Initially, the $\mathrm{Na}$ coverage on the $\mathrm{Si}(111) 3 \times 1$ surface was suggested below 0.01 monolayer (ML), and thus Fan and Ignatiev proposed that the $3 \times 1$ surface was due to the alkali metal impurity [1]. However, a scanning tunneling microscopy (STM) of this surface indicated that $\mathrm{Na}$ atoms formed an ordered layer [2,3]. The coverage of $\mathrm{Na}$ on the $\mathrm{Si}(111) 3 \times 1$ surface was studied using ion scattering [4] and photoemission peak intensity [5], and has been determined as 1/3 ML. A few structural models have been proposed for the $3 \times 1$ surface $[2,3,6,7]$. However, largely due to the fact that $\mathrm{Na}$ adsorbates are not visible in the STM image of the $3 \times 1$ surface, a unanimous structural model of the $\mathrm{Na} / \mathrm{Si}(111) 3 \times 1$ surface is not existing yet. The alkali metal induced $3 \times 1$ reconstruction not only occurs on the Si(111) surface but also on the $\mathrm{Ge}(111)$ surface [8]. While most of the studies to date have concentrated on the $3 \times 1$ surface on the $\mathrm{Si}$ surface, we present in this paper the results from our study of the $\mathrm{Na}$-adsorbed $\mathrm{Ge}(111)$ surface and the $\mathrm{Na}$-induced $3 \times 1$ surface. Na adsorbed on disordered sites at the early stage deposition, and $\mathrm{Na}$ did not form an ordered structure at the increased coverage. When the Na-adsorbed surface was annealed, the surface reconstructed to the $3 \times 1$ structure. A filled state surface image revealed a zigzag chain structure, while an empty state image showed a narrow line over the center of the zigzag chain.

\section{EXPERIMENTAL}

The experiment was performed using a UHV system equipped with LEED/AES and STM. A Ga-doped $\mathrm{Ge}(111)$ wafer was cleaned by repeated $\mathrm{Ar}^{+}$ion sputtering $(1 \mathrm{~mA} @ 500 \mathrm{~V})$ and annealing at $800^{\circ} \mathrm{C}$ until a sharp $c(2 \times 8)$ LEED pattern was achieved. Na was deposited using SAES getter [9]. The getter was outgassed thoroughly before dosing, and the pressure during $\mathrm{Na}$ evaporation was maintained below $2 \times 10^{-10}$ Torr. The Na coverage was controlled by Na dosing time. The Ge substrate was kept at room temperature during $\mathrm{Na}$ dosing, and to induce the $3 \times 1$ reconstruction the substrate was annealed at $300^{\circ} \mathrm{C}$ for several minutes. 


\section{RESULTS AND DISCUSSION}

\section{$3.1 \mathrm{Na} / \mathrm{Ge}(111) \mathrm{e}(2 \times 8)$}

At the initial stage of deposition (deposition time $=20 \mathrm{sec}$ ), $\mathrm{Na}$ atoms adsorbed at the defect sites or domain boundaries, as shown in Fig. 1 in which $\mathrm{Na}$ adsorbates appear as bright protrusions. The size of

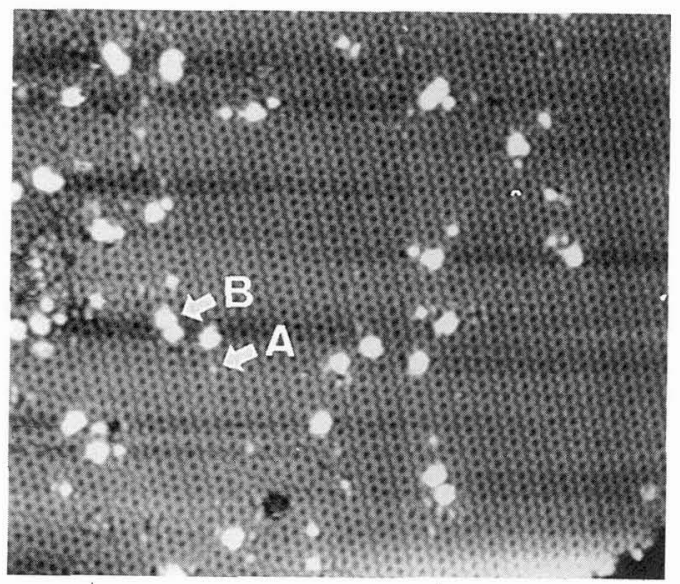

Figure 1: STM image of $\mathrm{Na}$ adsorbates on the Ge(111) surface. The $\mathrm{c}(2 \times 8)$ background is the Ge surface. Na adsorbates appear as bright protrusions in the filled state image. Mark A indicates a single atom adsorbate and B indicates a cluster. Bias $=-2.5 \mathrm{~V}$ to the sample.

the protrusions imaged indicated that $\mathrm{Na}$ adsorbed as both a single atom and a small cluster. The image shows that the stepedges are not a preferential site for $\mathrm{Na}$ adsorbates. The interesting result shown in Figs. 2 (a) and (b) is that, when the bias voltage was below $1 \mathrm{~V}, \mathrm{Na}$ adsorbates appear as protrusions in a filled state image, but as depressions in an empty state image.

On the $\mathrm{Si}(111) 7 \times 7$ surface, however, alkali metal atoms adsorbed as a single atom adsorbate, and appeared dark in both filled and empty state images when the coverage was low [10]. The difference between the two surfaces can also be found in the photoemission spectra [11]. The Si(111)7x7 surface is metallic because of the surface states related to the adatoms and rest atoms. When alkali metal atoms adsorb, the surface states located both above and below the Fermi energy quickly vanish turning the surface insulating [11], which is consistent with the STM observation [10]. The empty state tunneling spectrum obtained from the $\mathrm{Ge}(111) \mathrm{c}(2 \times 8)$ surface showed a dangling bonds-related peak close to the Fermi energy [12]. Since $\mathrm{Na}$ is an electron donor, $\mathrm{Na}$ adsorbates on the $\mathrm{Ge}(111) \mathrm{c}(2 \times 8)$ surface reacted with this state, causing the empty state image of the Na-reacted sites to appear dark. On the contrary, when alkali metal atoms were adsorbed on the Ge(111) surface, electron energy loss and photoemission studies showed that the surface states below the Fermi energy were replaced with the newly emerging interface states [13-15]. Soukiassian et al. attributed the hybridization of $\mathrm{Na} 3 s$ and $\mathrm{Ge} 4 p$ dangling bond orbitals as the origin of the interface state [15]. Based on these reports, we suggest that the protruded image of the Na adsorbates in the filled state image is due to the interface state below the Fermi energy. When the sample bias voltage was increased to $1.2 \mathrm{~V}, \mathrm{Na}$ adsorbates could be imaged, as shown in Fig. 2(c), because then the density of states were available for the imaging. Nevertheless, the image contrast is much weaker than the filled state image shown in Fig. 2(a). The bias voltage dependence of the present empty state images is similar to that of the oxygen-dosed Ge(111) surface [12]. At the increased coverage, $\mathrm{Na}$ atoms did not form an ordered structure. Fig. 3 is an image obtained

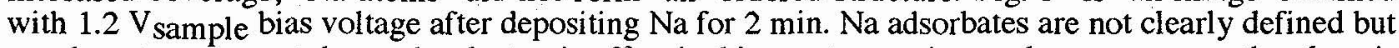
are almost transparent due to the electronic effect in this empty state image, but one can see that there is no ordering in the adsorbate arrangement. 


\subsection{Na-Induced $\operatorname{Ge}(111) 3 \times 1$}

When the Na-adsorbed $\mathrm{Ge}(111)$ surface was annealed at $300^{\circ} \mathrm{C}$, the $3 \times 1 \mathrm{LEED}$ pattern appeared. When the Na coverage was small, both $\mathrm{c}(2 \times 8)$ and $3 \times 1$ patterns were observed. When the Na coverage was increased, the $\mathrm{c}(2 \times 8)$ spots were completely replaced with the $3 \times 1$ spots. STM images also showed that
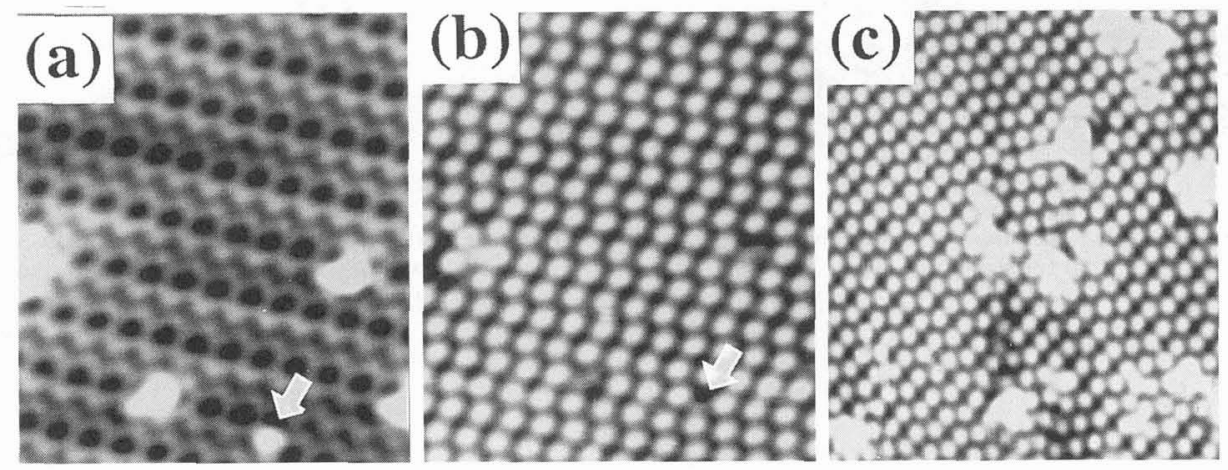

Figure 2: (a) and (b) were obtained simultaneously using opposite bias polarities. The two arrows in (a) and (b) mark the same position on the sample. (a) Na adsorbate appear as protrusions. Bias $=-0.86 \mathrm{~V}$ to the sample. (b)Na adsorption sites appear dark. Bias $=+0.86 \mathrm{~V}$ to the sample. (c)The same sample scanned with $1.2 \mathrm{~V}$ sample bias. Na adsorbates are now seen as protrusions.

the surface after annealing consisted of both $c(2 \times 8)$ and $3 \times 1$ structures, but the sized of the $3 \times 1$ area increased with increasing $\mathrm{Na}$ preadsorption coverage. Fig. 4 is an image showing both $\mathrm{c}(2 \times 8)$ and $3 \times 1$. $\mathrm{Na}$ was preadsorbed for $30 \mathrm{sec}$ for this surface, and annealing was done at $300^{\circ} \mathrm{C}$ for $5 \mathrm{~min}$. The $3 \times 1$ reconstruction started from the stepedge, which can be seen from the area marked with an arrow. This is similar to the Na-induced $3 \times 1$ reconstruction on the Si(111) surface [16]. The atomic image of the 3xl structure, i.e., the zigzag chains shown in the inset of Fig. 4, is also the same as that of the $\operatorname{Si}(111) 3 \times 1$ structure [4]. In fact, the two surfaces were the same in several respects: The zigzag chains were only shown in the filled state image, and in the empty state image narrow lines were imaged along the center of the zigzag chains. The width of the chains at the edge of a $3 \times 1$ island was half the regular zigzag chain width, indicating that these are a single atom chain. These similarities strongly suggest that the atomic

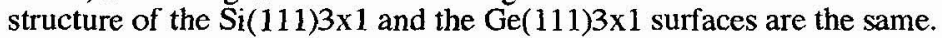

Fan and Ignatiev proposed that $\mathrm{Na}$ acted as an impurity to induce the $3 \times 1$ reconstruction [8]. However, the fact that the size of the $3 \times 1$ area depends on the amount of preadsorbed $\mathrm{Na}$ atoms indicates that $\mathrm{Na}$ atoms form an ordered structure. The Na coverage in the Na-induced $\mathrm{Si}(111) 3 \times 1$ surface has been determined as $1 / 3 \mathrm{ML}[4,5]$, which means that the atoms shown in the zigzag chains are Si atoms. The fact that the Si(111)3xl and $\mathrm{Ge}(111) 3 \times 1$ surfaces look the same under STM strongly suggests that the atoms shown in the present $\mathrm{Ge}(111) 3 \times 1$ surface are not $\mathrm{Na}$ but $\mathrm{Ge}$. Assuming that the Na coverage was 1/3 ML, Erwin [7] proposed a structural model of the Na-induced $\mathrm{Si}(111) 3 \times 1$ surface, which consisted of Pandey's $\pi$-bonded chain [17] and an additional single atom chain, as reproduced in Fig. 5(a). Although the total energy calculated was lowest for Erwin's model among the four models he considered [17], his model was not consistent with the angle resolved photoemission data [18]. Jeong and Kang proposed an alternative model, i.e., a missing top layer (MTL) model, as reproduced in Fig. 5(b) [19]. The energy difference between the Erwin's model and the MTL model is negligible [7, 19], but the MTL model is consistent with the band dispersion data.

In general, alkali metal adsorption activates the surface reactivity. However, the Na-induced $\mathrm{Si}(111) 3 \times 1$ surface is less reactive than the clean $\mathrm{Si}(111) 7 \times 7$ surface because of the passivation of the dangling bonds $[20,21]$. On the $\mathrm{Ge}(111)$ surface, however, the $3 \times 1$ surface reacted with oxygen more 


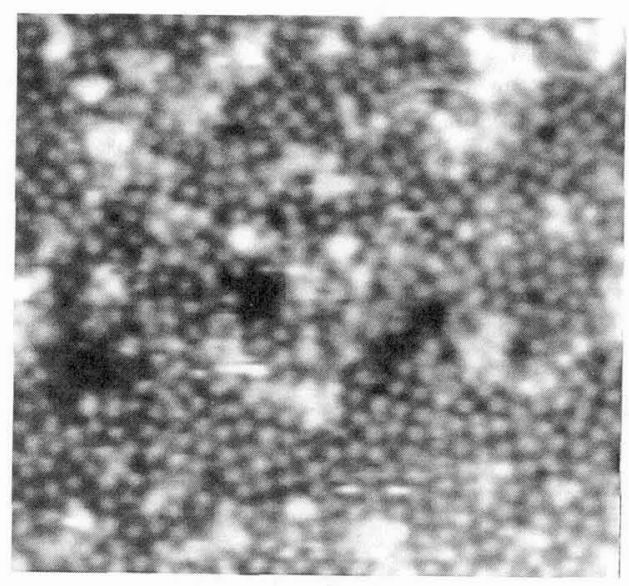

Figure 3: Image obtained after depositing more Na. $1.2 \mathrm{~V}_{\text {sample }}$ was used for scanning.

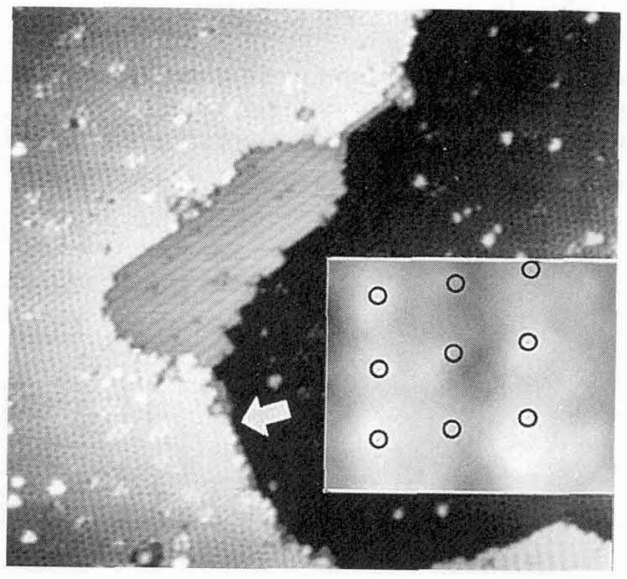

Figure 4: Surface containing both $c(2 \times 8)$ and $3 \times 1$ structure. Na was deposited for $30 \mathrm{sec}$, and the surface was annealed at $300^{\circ} \mathrm{C}$ for $5 \mathrm{~min}$. Sample bias structure, obtained with $-1.2 \mathrm{~V}$ applied to the sample. The magnified image is illustrated to help visualization.

than the clean surface. This can be seen in Fig. 6, which is an STM image of both the $c(2 \times 8)$ and the $3 \times 1$ structures obtained after dosing $50 \mathrm{~L}$ of oxygen. The unreconstructed Ge surface is relatively intact, while the $3 \times 1$ area is now disordered compared with the original $3 \times 1$ surface. This indicates that the NaGe bonding in the $3 \times 1$ surface is much weaker than the Na-Si bonding on the $\mathrm{Si}(111) 3 \times 1$ surface.

In Erwin's model shown in Fig. 5(a), there are three Si atom chains in each $3 x$ unit row. Among these, however, only two Si chains which are closest to the $\mathrm{Na}$ chain are visible (i.e., a zigzag double chain) in the filled state image because of the strong bonding between $\mathrm{Na}$ and nearest neighbor $\mathrm{Si}$ [7]. If this is the case, we might be able to observe triple chains after oxygen dosing on the $3 \times 1$ surface since oxygen dosing will alter the nature of $\mathrm{Na}-\mathrm{Si}$ bonding. However, our results were negative. In Fig. 7, we show atomic images of the $3 \times 1$ surface obtained after dosing $50 \mathrm{~L}$ of oxygen. The empty state image shown in Fig. 7(a) now reveals atomic features, but both empty and filled state images show a double chain structure. Although we cannot completely rule out a possibility that the double chain image is caused by a new electronic effect induced by oxygen dosing, our results support the MTL model [19], in which there are originally two Si atom chains in each $3 x$ unit row.

\section{CONCLUSION}

We have studied the atomic structure of the $\mathrm{Na} / \mathrm{Ge}(111)$ surface. $\mathrm{Na}$ atoms adsorbed initially on defect sites as a single atom adsorbate or as a cluster. Na atoms did not form an ordered structure at all coverages. When the surface was annealed after $\mathrm{Na}$ adsorption, the surface reconstructed to the $3 \times 1$ structure. The STM images of the Ge(111)3x1 surface were similar to those of the Na-induced $\mathrm{Si}(111) 3 \times 1$ surface. Against oxidation the $\mathrm{Ge}(111) 3 \times 1$ surface was more reactive than the clean $\mathrm{Ge}(111) \mathrm{c}(2 \times 8)$ surface. Both filled and empty state images obtained after oxygen dosing revealed double atom chains. 

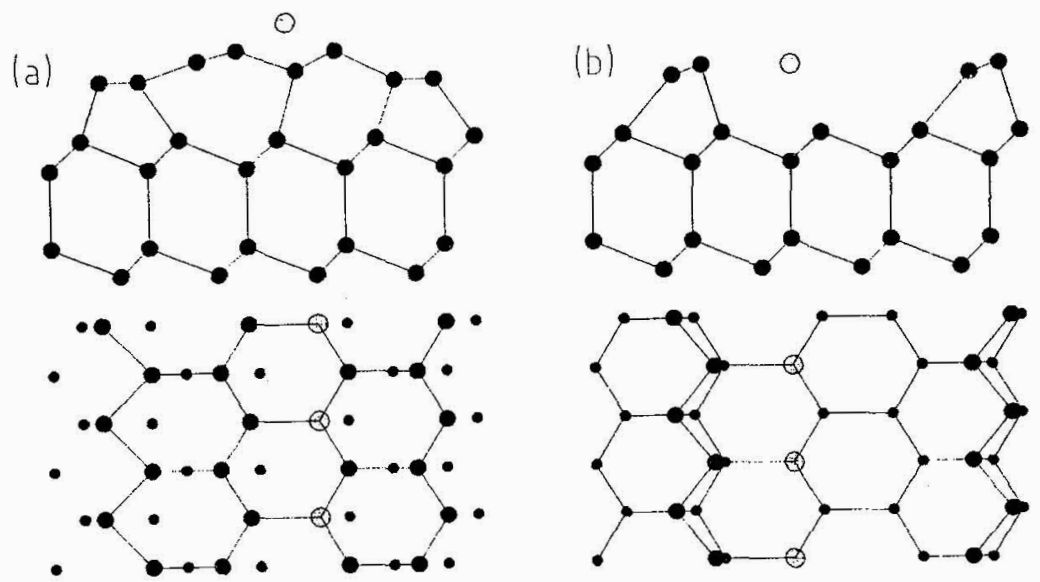

Figure 5: Structural models of the Na-induced Si(111)3x1 surface. For both models, Na coverage is $1 / 3 \mathrm{ML}$. (a) Modified Pandey's chain model proposed by Erwin. Because of the charge transfer from $\mathrm{Na}$ to $\mathrm{Si}, \mathrm{Si}$ atom double chains are imaged in a filled state STM image. (b)Missing top layer model proposed by Jeong and Kang.

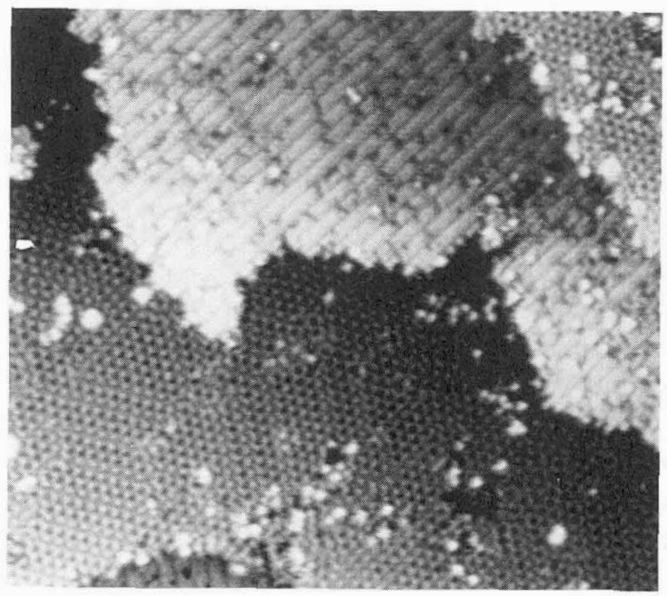

Figure 6: STM image obtained after dosing $50 \mathrm{~L}$ of oxygen at room temperature. Bias voltage was $-1.2 \mathrm{~V}_{\text {sample }}$ 

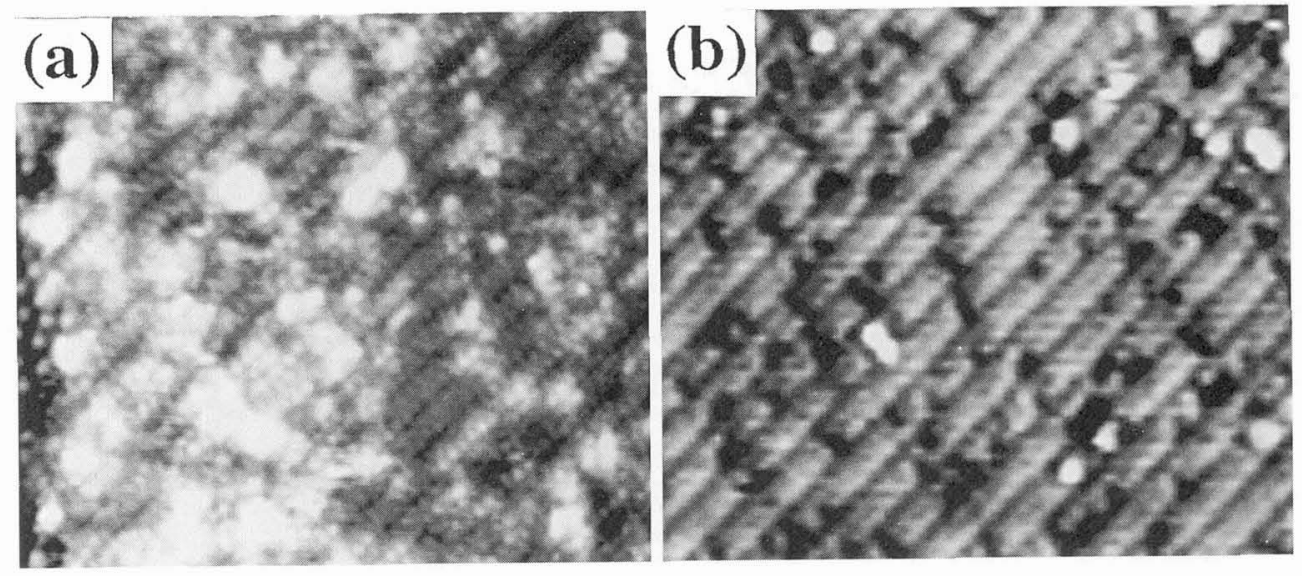

Figure 7: Atomic images of Na-induced $\mathrm{Ge}(111) 3 \times 1$ surface obtained after dosing $50 \mathrm{~L}$ of oxygen. (a) was obtained with $1.2 \mathrm{~V}_{\text {sample }}$ bias and $(\mathrm{b})$ with $-1.2 \mathrm{~V}_{\text {sample. }}$. Both images show double chains.

\section{Acknowledgments}

We are grateful for useful discussions with professors M. H. Kang, J. M. Seo, and R. F. Willis. D. Jeon acknowledges the support by the Korea Science and Engineering Foundation through the AtomicScale Surface SRC and by the Korean Ministry of Education through BSRI Project No. N96095.

\section{References}

[1] Fan W. C. and Ignatiev A., Phys. Rev. B 41 (1990) 3592-3595.

[2] Jeon D., Hashizume T., Sakurai T., and Willis R. F., Phys. Rev. Lett. 69 (1992) 1419-1422.

[3] Wan K. J., Lin X.F., and Nogami J., Phys. Rev. B 46 (1992) 13635-13638.

[4] Hashizume T., Katayama M., Jeon D., Aono M., and Sakurai T., Jpn. J. Appl. Phys. 32 (1993) L1263-1265.

[5] Pagel J., Theis W., Haak, H. and Horn K., J. Vac. Sci. Technol. B 11 (1993) 1439-1442.

[6] Jeong S. and Kang M. H., Phys. Rev. B 51 (1995) 17635-17641.

[7] Erwin S. C., Phys. Rev. Lett. 75 (1995) 1593-1996.

[8] Fan W. C.and Ignatiev A., Phys. Rev. B 40 (1989) 5479-5483.

[9] Commercial getter from SAES getters, Milano, Italy.

[10] Jeon D., Hashizume T., and Sakurai T., Appl. Surf. Sci. 94/95 (1996) 493-496.

[11] Magnusson K. O. and Reihl B., Phys. Rev. B 41 (1990) 12071-12075.

[12] Klitsner T., Becker R. S., and Vickers J. S., Phys. Rev. B 44 (1991) 1817-1824.

[13] Arts J., Hoeven A. J., and Larsen P. K., Phys. Rev. B 37 (1988) 8190-8197.

[14] Surnev L. N., J. Electron. Spectrosc. Relat. Phenom. 53 (1982) 53-63.

[15] Soukiassian P. , Kendelewicz T., and Hurych Z. D., Phys. Rev. B 40 (1989) 12570-12573.

[16] Jeon D., Hashizume T. , Wang X., Bai C., Motai K., and Sakurai T., Jpn. J. Appl. Phys. 31 (1992) L501-504.

[17] Pandey K. C., Phys. Rev. Lett. 47 (1981) 1913-1917.

[18] Sakamoto K. , Okuda T., Nishimoto H., Daimon H., Suga S., Kinoshita T., and Kakizaki A., Phys. Rev. B 50 (1994) 1725-1732.

[19] Jeong S.and Kang M. H., Phys. Rev. B, in press.

[20] Tikhov M., Surnev L., and Kiskinova M., Phys. Rev. B 44 (1991) 3222-3225.

[21] Jeon D., Hashizume T., and Sakurai T., Jpn. J. Appl. Phys. 32 (1993) 1423-1427. 